\title{
Model project for establishing an avalanche warning and evacuation system
}

\author{
HIDEKI TERADA, \\ Public Works Research Institute, 1 Asahi, Tsukuba, Ibaraki 305, Japan \\ KAZUNORI FUJISAWA, \\ Public Works Research Institute, 6-8, 2 Chome, Nishiki-cho, Arai, Niigata 944, Japan \\ Yoshimitsu NAKAMURa, \\ Public Works Research Institute, 1 Asahi, Tsukuba, Ibaraki 305, Japan \\ NORIYUKI MINAMI \\ Ministry of Construction, 2-1-3, Kasumigaseki, Chiyoda Ward, Tokyo 100, Japan
}

\begin{abstract}
A project was started in 1990 to rationalize the avalanche warning and evacuation system. The major items in the model project were: (1) zoning methods for dangerous areas; (2) establishment of a surveillance system; and (3) methods of determining a warning and evacuation standard. Since the scale of a snow avalanche cannot be predicted, areas with more than $30 \mathrm{KN} \mathrm{m}^{2}$ of impact are identified. Equipment for conducting automatic surveillance and data processing was developed to telemeter snow and weather data. Issuing warning or evacuation advice is the focus of the discussion. Judgment is based on information on current conditions obtained from a telemeter and from residents, and on information provided by forecasts of snowfall and temperatures until the following morning. Two methods of judgment are under consideration: one is to set out a standard value based on meteorological data obtained by observation, the other is based on a discriminant of danger level.
\end{abstract}

\section{INTRODUCTION}

Snow avalanche disasters in Japan tend to occur frequently in the years with heavy snowfall, for example 1981 and 1984. This new project was designed to protect towns and villages from avalanches. It is almost impossible to provide all towns and villages with protection facilities since there are many at risk. The purpose of the current project is to rationalize warning and evacuation systems. This paper reports on a model project for this purpose.

Under the "Disaster countermeasures basic act", mayors and town and village headmen must order residents to evacuate in the face of disaster. No standard has yet been established for giving such an order. Here we examine a model project for the establishment of a standard, and for systemization of the means of information transfer.

Items under examination fall into three categories: (1) zoning of threatened areas, including examination of the concept of dangerous areas and establishment of zoning methods; (2) establishment and examination of a surveillance system for collection of information on the danger level; and (3) establishment and examination of the concept of a warning standard and practical methods to establish the standard.

Six districts with heavy snowfalls have been selected for examination. Areas range from 20 to $50 \mathrm{~km}^{2}$ which includes 10-30 slopes threatened by avalanches. The length of the slopes varies from around $50 \mathrm{~m}$ to over $1000 \mathrm{~m}$ (Table 1). Some of these districts are hit frequently by avalanche disasters, others less so.

\section{ZONING OF DANGEROUS AREAS}

In Switzerland and other countries with long records of avalanches, zoning of dangerous areas is based on these records, giving consideration to the impact produced. In Japan such records are rarer, and zoning is based on the empirical method of Takahashi (1960) and on numerical calculations. Where numerical calculations are employed, it is necessary to clarify the targeted snow avalanche.

By Takahashi's method, the angle of elevation, which is obtained by projecting directly to the starting point of an avalanche from the termination of debris, is $18^{\circ}$ for a surface-layer avalanche and $24^{\circ}$ for a full-depth avalanche. These values are based on the minimum values 
Terada and others: An avalanche warning and evacuation system

Table 1. Condition of the districts selected for observation

Selected districts

Snow-avalanche threatened slopes

Spread of the selected districts

$\begin{array}{ccc}\begin{array}{c}\text { Number of } \\ \text { slopes }\end{array} & \begin{array}{c}\text { Slopes at high } \\ \text { danger level }\end{array} & \begin{array}{c}\text { Horizontal } \\ \text { spread }\end{array} \\ \text { slopes } & \text { slopes } & \mathrm{m}\end{array}$

Vertical

spread

$\mathrm{m} \quad \mathrm{km} \times \mathrm{km}$

\begin{tabular}{|c|c|c|c|c|c|}
\hline Masuda-town, Akita & 14 & 7 & $50 \sim 500$ & $50 \sim 400$ & $15 \times 3$ \\
\hline Yunotani-village, Niigata & 27 & 27 & $50 \sim 500$ & $50 \sim 500$ & $10 \times 2.5$ \\
\hline Otari-village, Nagano & 28 & 23 & $50 \sim 600$ & $50 \sim 350$ & $7 \times 3$ \\
\hline Ohno City, Fukui & 15 & 13 & $100 \sim 1500$ & $30 \sim 700$ & $10 \times 4$ \\
\hline Ajigasawa-town, Aomori & 14 & 9 & $50 \sim 500$ & $30 \sim 150$ & $18 \times 3$ \\
\hline Nango-village, Fukushima & 10 & 6 & $100 \sim 500$ & $100 \sim 300$ & $9 \times 3$ \\
\hline
\end{tabular}

obtained from many avalanches, to which safety values of $10 \%$ are added.

Figure 1 shows the zoning method being examined at present. A dangerous area is zoned by two lines. The outer line indicates the maximum run-out limit of avalanches, defined by whichever of the following three methods provides the widest area: (1) a method in which the angle of depression from the starting point becomes $18^{\circ}$; (2) a method by numerical calculation for an avalanche with a 50-year return period; or (3) a method based on outer limits of avalanches which have occurred in the past.

To set the extent of the run-out zone, the shapes of 80 avalanches were examined. The maximum spread angle on one side from an avalanche path is $30^{\circ}$, but in half of the records the shape of run-out zones was straight. Considering that the outer line indicates the maximum run-out limit, $30^{\circ}$ on one side was taken for the maximum angle of extent of spread.

The area inside the inner line is where $30 \mathrm{KN} \mathrm{m}^{2}$ of impact is expected to be received, which is based on a numerical calculation. Because the scale of an expected snow avalanche cannot be accurately predicted, this area is an indication of where particularly high damage is anticipated. We tried to define the impact force value of the inner line as that which would destroy a Japanese

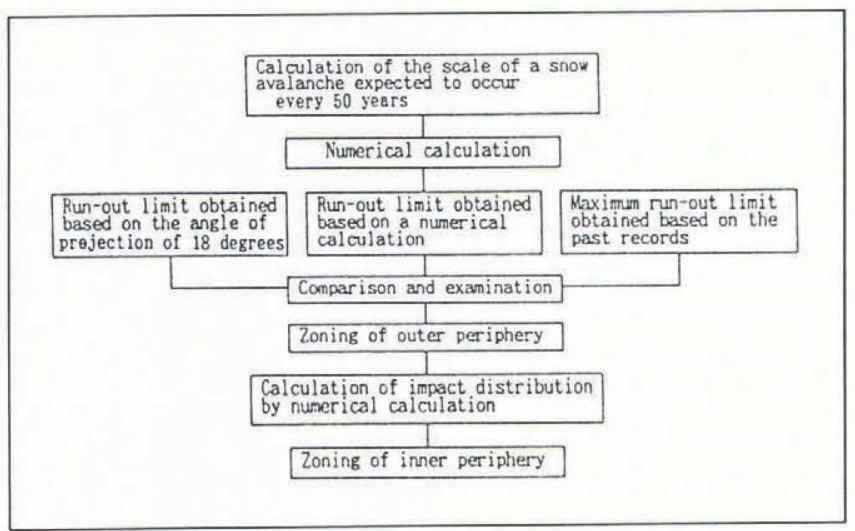

Fig. 1. Zoning procedures. wooden house, but data were insufficient. The value was set instead by considering potential damage indicated by Perla and Martinelli (1976) and the value of the Swiss red zone.

A model by Perla and others (1980) was used for the numerical calculation. Their calculation formula is

$$
\mathrm{d} u / \mathrm{d} t=g(\sin \theta-\mu \cos \theta)-U^{2} /(M / D),
$$

where $\mu$ is the coefficient of friction and $M / D$ is a massto-drag ratio. A method for estimating these two parameters was needed and Perla and others indicated that these parameters simulated recorded avalanche data well. Therefore we obtained the parameters by simulating 47 avalanche records in Japan. However, for simplification we applied the relationship between $\mu$ and velocity which Schaerer (1975) assumed. This relationship is

$$
\mu=5\left(\mathrm{~ms}^{-1}\right) u^{-1} \quad\left(u \leq 10 \mathrm{~m} \mathrm{~s}^{-1}\right) .
$$

Also, we supplemented the range of $0 \leq u<10 \mathrm{~m} \mathrm{~s}^{-1}$ by

$$
\mu=-0.01 u+0.6 \quad\left(0 \leq u<10 \mathrm{~m} \mathrm{~s}^{-1}\right),
$$

where $\mu=0.6$ was set by considering experimental data relating to the friction coefficient of snow blocks on slopes. We assumed the value of $\mu$ changed linearly from $\mu=0.6$ to $\mu=0.5$ when $u=10 \mathrm{~m} \mathrm{~s}^{-1}$.

Therefore, the unknown parameter became $M / D$.

According to Perla (1980), $M(\mathrm{~kg})$ is the mass of the avalanche and $D\left(\mathrm{~kg} \mathrm{~m}^{-1}\right)$ is composed of three resistive terms. It is expressed as

$$
D(s)=\mu M / r+\mathrm{d} M / \mathrm{d} S+k,
$$

where $r$ is the local radius of curvature, $s$ is the position of the centre of mass measured along the path from the reference position at the top of the path, and $k$ is the drag and ploughing term which is proportional to the increase of the avalanche surface area. All terms composed of $M / D$ had $M$ or the geometrical scale of an avalanche (such as $k$ ). Therefore we assumed that $M / D$ could be estimated by the volume of avalanche.

First, values of $M / D$ were found to fit the run-out distance of past avalanches and the volume of each 
avalanche was estimated. The relationship between the volume of the avalanche and $M / D$ was examined. Since 47 dry-surface avalanches were used, we evaluated $M$ (mass of the avalanche) from the volume of the avalanche, because the density range of avalanches seemed not to vary widely.

The distribution of $M / D$ became wider when the avalanche volume increased. For instance, when avalanche volume was $400-1000 \mathrm{~m}^{3}, M / D$ was $50-250 \mathrm{~m}$. When avalanche volume was $100000-200000 \mathrm{~m}^{3}, M / D$ was $150-1700 \mathrm{~m}$.

Also, the highest value of $M / D$ became larger when avalanche volume increased, especially when avalanches ran down long slopes. For instance, when slope length (for slopes over $10^{\circ}$ ) was less than $1500 \mathrm{~m}$, avalanche volume was about $200000 \mathrm{~m}^{3}$ which corresponded to the highest value of $M / D$ (about $1100 \mathrm{~m})$. When slope length was longer than $1500 \mathrm{~m}$, the volume (about $200000 \mathrm{~m}^{3}$ ) corresponded to the highest value of $M / D$ (about $1700 \mathrm{~m})$.

The result that $M / D$ (at least for the highest $M / D$ values) became larger as the avalanche increased in volume seemed to confirm the tendency for larger-scale avalanches to run longer distances, because an increase of $M / D$ reduced the resistive force. Therefore this relationship between the size of the avalanche and the highest value of $M / D$ was used for estimating $M / D$. The value of $M / D$ can be obtained by calculating the volume of snow which corresponds to the 50-year return period, which is then applied to this correlation.

The scale of the snow avalanches used for the numerical calculation is determined to be of 50-year return period due to the fact that the data available concerning the snowfall and snow cover have accumulated during the past several decades. Accordingly, the scale cannot be determined to be any larger, and

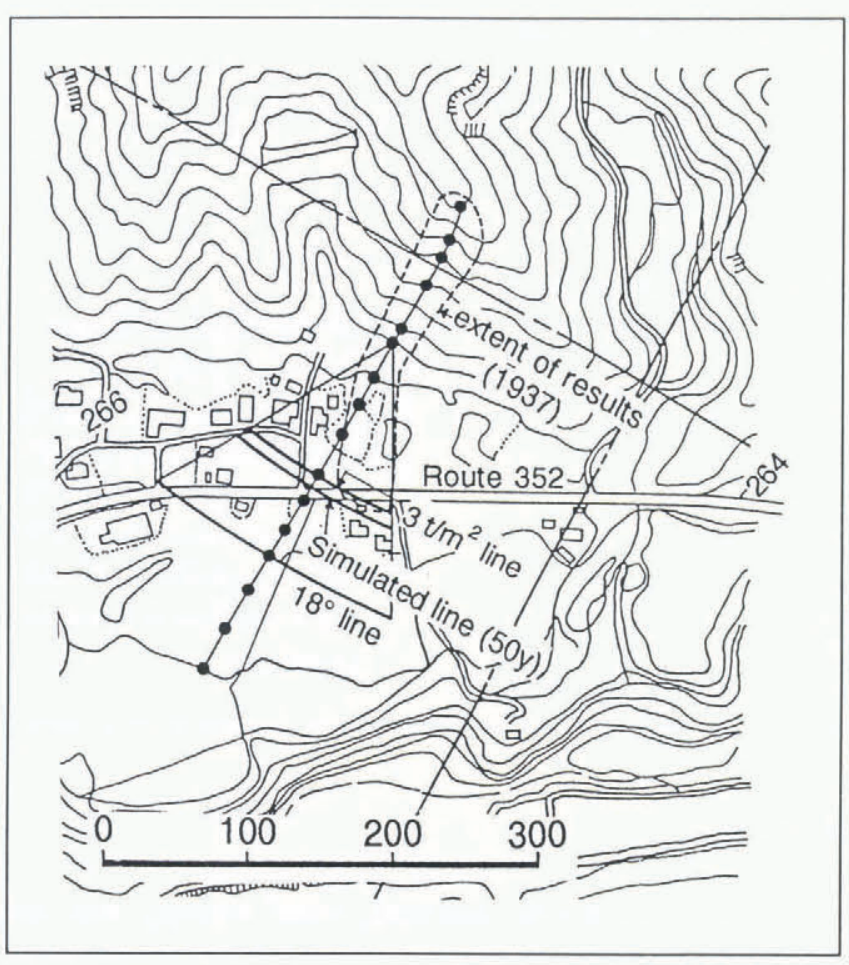

Fig. 2. Example of examination of zoning. precision cannot be expected to increase; additionally there is a limit in the thickness of the layers where snow avalanches are expected to occur.

Figure 2 shows an example of an outcome of zoning which was conducted on a trial basis. So far this zoning method has been used for 18 slopes. The outer line for 14 slopes was found by the $18^{\circ}$ rule, for 3 by calculation and for 1 by the extent of past avalanches.

\section{SURVEILLANCE SYSTEM}

The surveillance system for roads in Japan, involving regular patrols carried out by inspectors, provides useful information for understanding slope conditions and discovering avalanches. As part of avalanche protection measures for hamlets in the Niigata Prefecture, patrolmen are assigned to watch danger areas. Senior residents and district headmen of hamlets are often appointed to be patrolmen due to their comprehensive knowledge of the area. Nevertheless, the number of patrolmen is limited and their views may be obstructed during snowfall or at night. For this reason a supplementary surveillance system is required. Except for some expressways and national roads where avalanche surveillance is regularly conducted, no system has been hitherto established for the purpose of avalanche watching. Accordingly, a telemeter system (Fig. 3) has been provided to systematize automatic observation of snowfall and snow-cover data at particular stations. Data are transmitted to monitor stations, where they are processed for danger-level analyses. Major observational items are temperature, wind direction, wind velocity, depth of snow and insolation. Sensors were selected by considering climatic elements used in discrimination analysis and found to influence avalanche occurrence. Data on wind direction and solar radiation, not used at present in discrimination analysis, will be analyzed for improving the discrimination method. The measuring range of snow-depth meters, over $6 \mathrm{~m}$, was set by considering snow-depth records of avalanche disasters. Data observed at $10 \mathrm{~min}$ intervals at several observation stations are transmitted automatically to a monitor station in real time, where they are displayed by time-series graphs. Data can be displayed for one-day or one-week periods in combination with past data concerning snow avalanches and standard values used for judgment. Several formulae for estimating a danger level index of snow avalanches are programmed into the system; the danger level index is calculated and displayed on the same screen. When the index reaches a certain predetermined danger level, an alarm goes off.

\section{WARNING AND EVACUATION STANDARD}

Since there are no practical or legally based standards for issuing and calling off official warnings and orders (Izumi and Nakagawa, 1989), municipalities at present are greatly concerned about ordering their residents to exercise precaution or to evacuate their homes in the face of danger.

In general, information concerning a disaster is collected and analyzed by the prefectural body in 

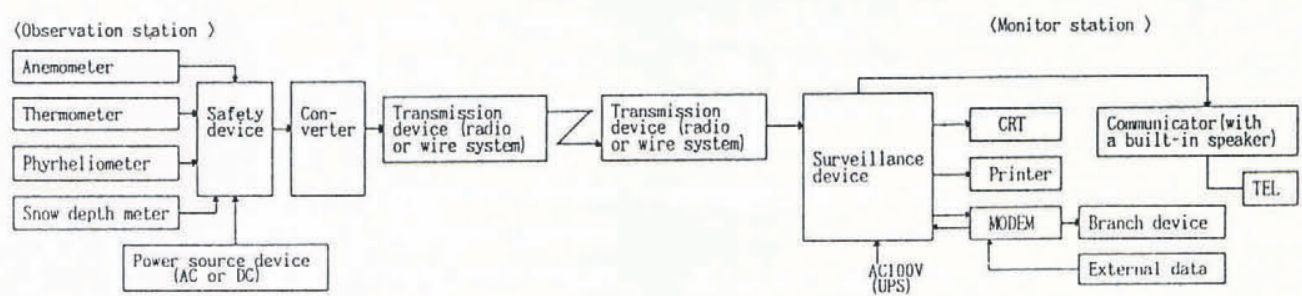

Fig. 3. Example of a flow chart of the system.

charge, and is offered to mayors who are authorized to give precautionary advice and evacuation orders to the residents. Accordingly, the content and significance of the information offered to the mayors is of great importance. The information supplied can be classified as follows:

(1) present condition of the snow cover and meteorological conditions obtained from the telemeter;
(2) present slope conditions such as cornice, snow fold, occurrence of snow avalanches, and conditions of snowfall, snow cover and weather obtained from patrolmen and residents;

(3) forecasts of snow accumulation and temperature over the next $24 \mathrm{~h}$. The danger level of the present situation is judged based on information (1) and (2), and the change of situation thereafter is based on the forecasts.

Table 2. Classification of avalanche danger level (Japan Road Corporation, 1990)

\begin{tabular}{|c|c|c|c|}
\hline $\begin{array}{l}\text { Avalanche } \\
\text { danger level }\end{array}$ & $\begin{array}{l}\text { Control } \\
\text { system }\end{array}$ & Actual operation & $\begin{array}{c}\text { Standard for reference to classify avalanche } \\
\text { danger level }\end{array}$ \\
\hline
\end{tabular}

I

Attention system

II

Precaution system

III

Enforced
precaution
system

Collecting information on other organizations

Beginning of avalanche patrol ${ }^{2}$

Observation of settlement rate of snow cover

Collecting information on other organizations

Enforcement of avalanche patro (increase of patrolmen and frequency)

Checking experimental value of experts $^{3}$

Observation of settlement rate over $-100^{4,5}$
of snow cover
Collecting information on other
organizations
Arrangement of avalanche patrol
and avalanche experts
Referring to experts
Discussing traffic restriction
Operating or its removal

Danger index ${ }^{1} \quad$ Experimental value of experts

$-1000 \sim-500$

$-500 \sim-100$
(1) Snow depth $\geq 250 \mathrm{~cm}$

(2) Snowfall $\geq 40 \mathrm{~cm} \mathrm{~d}^{-1}$

(3) Settlement rates $\leq 20 \%$

(4) Wind velocity $\geq 7 \mathrm{~m} \mathrm{~s}^{-1}$ (over $4 \mathrm{~h}$ or $\geq 12 \mathrm{~m} \mathrm{~s}^{-1}$ )

(5) Air temperature $\leq-5^{\circ} \mathrm{C}$

(6) When condition of old snow surface is crust or hail layer

${ }^{1}$ Danger index value is generally calculated every hour.

${ }^{2}$ Standard of avalanche patrol frequency depends on separate table.

${ }^{3}$ Note especially snowfall, air temperature and wind velocity.

4 Discuss traffic restrictions, etc., when more than 3 factors within snow depth, snowfall, wind velocity and air temperature exceed the standard value.

${ }^{5}$ Note approaching condition to danger index of 0 . 
There seem to be two methods for judging the present danger level: setting a standard for the observed data themselves, and using a discriminant. A helpful example is shown in Table 2 (Kanazawa Administrative Station, 1990), which was prepared for the protection of an expressway. The danger index (DI) is obtained by a discriminant, while the experimental value of experts is a decision-making standard based on the measured data. In addition, actual operations to be executed depend on each danger level as stated in the table.

A method involving a discriminant function (Ministry of Construction, 1989) and one using composite critical values of meteorological elements (Hokuriku Technological Office, unpublished) are being examined for use in the discrimination of danger level. These are analyzed statistically, based on snow-cover and meteorological data from past snow avalanches. The elements used are temperature, snowfall and depth of snow in the former, and temperature, snowfall, depth of snow and wind velocity in the latter.

These two methods have been evaluated by comparing DI of dates when avalanches were and were not recorded. By this analysis, there are some dates when DI was low. Some basic reasons are that measuring sites of climate condition were different from those where avalanches actually occurred, and that the statistical method does not consider the structural condition of snow cover. Also, parameters of the two methods could not be examined well in each area due to a lack of avalanche records.

Forecasts of snowfall and temperature are used for judging whether present weather conditions will improve. Concurrently, snowfall and maximum and minimum temperature from $0900 \mathrm{~h}$ of the day until $0900 \mathrm{~h}$ of the following day are obtained around noon of the first day (Shimomura, 1988). Based on this information, the change in the level of danger until the following morning is assessed. The forecast is calculated for each model district based on an aerological synoptic chart released by the Japan Meteorological Agency. This method statistically analyzes the relationship between the aerological synoptic chart and actual values of snowfall and temperature measured in selected districts. The flow of information is as shown in Figure 4.

\section{CONCLUSION}

Major points are the zoning of dangerous areas, establishment of a surveillance system, and determination of a warning and evacuation standard. The zoning of dangerous areas is based on both the major damage zone and the maximum run-out limit. Major damage zones are expected to receive $30 \mathrm{KN} \mathrm{m}^{2}$ of impact in order to warn residents, but the scale of an expected snow avalanche cannot be predicted. A telemeter system is needed in addition to manual surveillance and the equipment to conduct automatic observation and data processing was developed. Both the time and method used for judgments are important. Warnings are based on the present conditions obtained from telemetry and from residents, as well as forecasts of snowfall and temperature until the

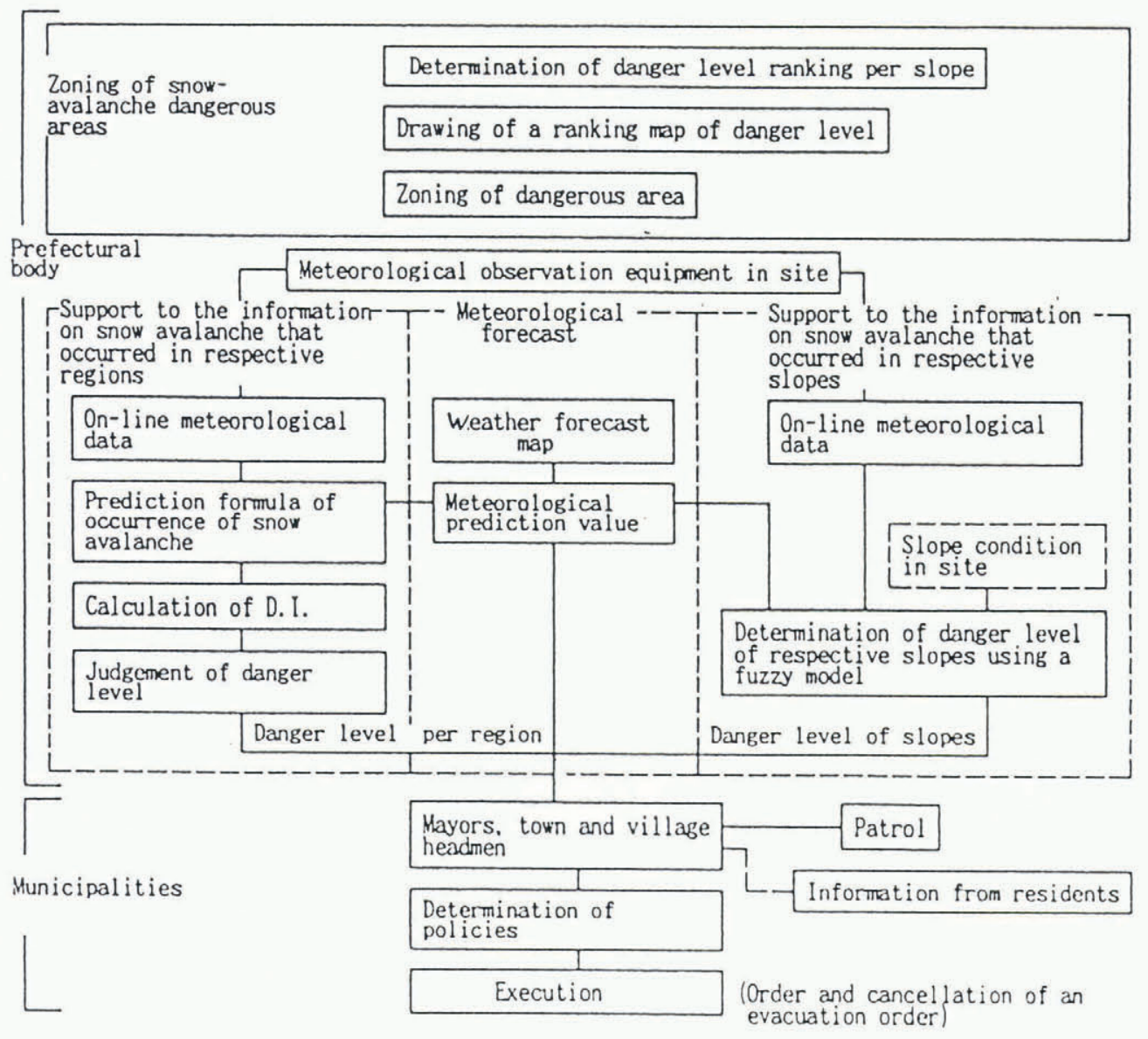

Fig. 4. Image chart of information for warning and evacuation advice. 
following morning. The present danger level is judged based on the former, and the direction of the change expected by the following morning is judged by the latter.

\section{REFERENCES}

Hokuriku Technological Office, Ministry of Construction. Unpublished. Report on the investigation of the countermeasures for snow avalanche protection for fiscal year 1988.

Izumi, K. and Y. Nakagawa. 1989. Present condition of precaution and evacuation system for avalanches in Niigata Pref. Proceedings of the Japanese Society of Snow and Ice 1989, 29.

Kanazawa Administrative Station, Japan Road Corporation. 1990. Examination of control method for avalanche prevention. Hokuriku Technological Report $54,31-36$.

Ministry of Construction. 1989. A study on prediction of occurrence of snow avalanches. In Proceedings of Assigned
Theme in the Common Division of the 43rd Technological Research Association of the Ministry of Construction. Tokyo, Ministry of Construction, 8-24.

Perla, R.I. and M. Martinelli, Jr. 1976. Avalanche handbook. U.S. Dep. Agric. For. Serv. Handb. 489.

Perla, R. I., T.T. Cheng and D. M. McClung. 1980. A two-parameter model of snow-avalanche motion. $\mathcal{F}$. Glaciol., 26(94), 197-207.

Schaerer, P.A. 1975. Friction coefficients and speed of flowing avalanches. International Association of Hydrological Sciences Publication 114 (Symposium at Grindelwald 1974 - Snow Mechanics), 425-432.

Shimomura, C. 1988. Development of the method for prediction of meteorological information - prediction of snowfall. Civil Engineering Journal (Tsukuba, Japan), 30(11), 15-20.

Takahashi, K. 1960. Damage caused by snow avalanche. Seppyo. 7. Jpn. Soc. Snow Ice, 22(1), 7-9. [In Japanese.]

The accuracy of references in the text and in this list is the responsibility of the authors, to whom queries should be addressed. 